\title{
Dual-Resonant Implantable Circular Patch Antenna for Biotelemetry Communication
}

\author{
Rongqiang $\mathrm{Li}^{1,2}$ and Shaoqiu Xiao ${ }^{1}$ \\ ${ }^{1}$ School of Physical Electronics, University of Electronic Science and Technology of China (UESTC), Chengdu 610054, China \\ ${ }^{2}$ School of Electronic Engineering, Chengdu University of Information Technology (CUIT), Chengdu 610225, China \\ Correspondence should be addressed to Rongqiang Li; liyq2011@cuit.edu.cn
}

Received 23 March 2016; Revised 22 April 2016; Accepted 9 May 2016

Academic Editor: Giuseppe Mazzarella

Copyright (c) 2016 R. Li and S. Xiao. This is an open access article distributed under the Creative Commons Attribution License, which permits unrestricted use, distribution, and reproduction in any medium, provided the original work is properly cited.

\begin{abstract}
A compact broadband implantable circular patch antenna is designed and experimentally demonstrated for Medical Implant Communications Service (MICS) band (402-405 MHz). Compared with other similar implantable antennas, the proposed antenna incorporates three advantages for biotelemetry communication. First, it can realize a broad impedance bandwidth by exhibiting dual resonances. Second, it can obtain a compact structure by introducing two arc-shaped slots, a rectangular slot and a circular slot on metal radiating patch. Finally, it can display a friendly shape by using a circular structure. The proposed antenna occupies a volume of about $431.5 \mathrm{~mm}^{3}\left(10.4^{2} \times 1.27 \pi \mathrm{mm}^{3}\right)$, which is a compromise between miniaturization and bandwidth. The measured $-10 \mathrm{~dB}$ impedance bandwidth is $55 \mathrm{MHz}(385-440 \mathrm{MHz})$. Furthermore, the radiation performance and human body safety consideration of the antenna are examined and characterized.
\end{abstract}

\section{Introduction}

Recently, there is a growing scientific interest in implantable biotelemetry communication for monitoring physiological parameters and treating human diseases. An implantable antenna is a critical component as physiological signals are transmitted wirelessly between implantable medical devices and exterior equipment [1-4]. MICS band and ISM (industrial, scientific, and medical) band $(2400-2480 \mathrm{MHz})$ are two common frequency bands for biotelemetry communication. In this study, we chose the MICS band to design an implantable antenna.

Designing an implantable antenna inside human body faces many challenges, such as miniaturization, bandwidth, biocompatibility, patient safety, and good radiation performance. Nowadays, printed planar inverted-F antennas (PIFAs) have been used to design implantable antennas by many researchers due to their own advantages such as small size and omnidirectional radiation pattern [5-10]. Miniaturization is a key requirement owing to some strict constraints on implantable antenna size. In [5], a compact spiral microstrip implantable antenna was proposed. In [6], miniaturization of the implantable antenna was realized by etching a meandered slot on the top metal patch with one end open. In [7], a miniaturized implantable antenna was designed by using meandering and shorting strategy. On the other hand, the implantable antenna needs a wide impedance bandwidth to avoid frequency shift due to intersubject variations of the electrical property of human body tissues and inaccuracies of fabrication and test. To broaden the antenna impedance bandwidth, some methods have been used. A pi-shape with double L-strips PIFA was proposed for implantable biotelemetry in [8], but this antenna had a relatively large volume. An implantable broadband low SAR antenna was proposed by combining a sigma-shaped monopole radiator and a novel C-shaped, coupled ground [9]. Reference [10] proposed a conformal broadband dipole antenna, whose bandwidth can reach $36.1 \%$. As shown above, the aforementioned antennas are all of rectangular shape, and they have sharp angles and edges. Compared with the rectangular antenna, a circular antenna has more friendly shape [11], and it can avoid injury to human tissues when it is directly exposed to the human body [12]. In [11], a miniaturized stacked circular implanted PIFA was designed 


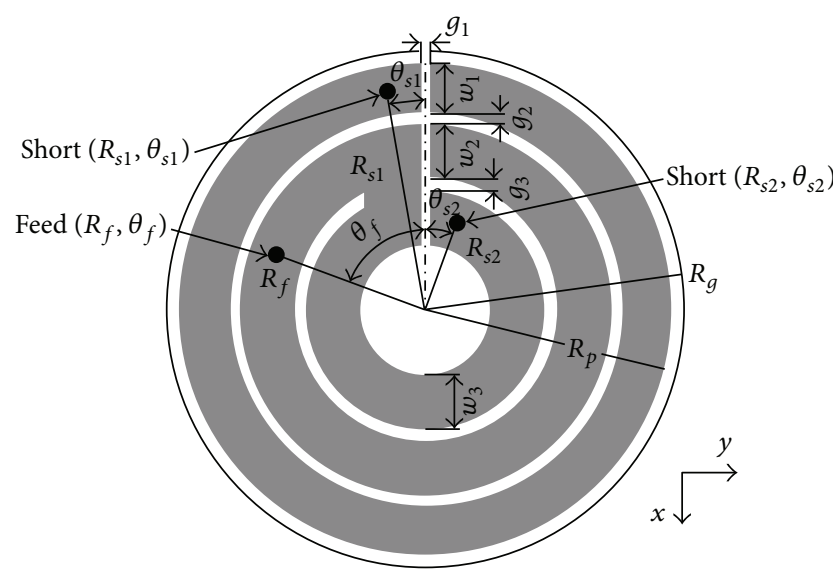

FIGURE 1: The geometry of the proposed implantable antenna.

by cutting some linear slots on two-layer radiating patches. However, the stacked PIFA usually has a high profile and a complex structure.

In this paper, a novel circular antenna with a single-layer radiating patch is proposed for biotelemetry communication. By properly embedding two arc-shaped slots, a rectangular slot and a circular slot on a circular radiating patch, the designed antenna can realize a compact, friendly, and dualresonant broadband structure. The detailed characteristics and experimental results of this antenna are presented and discussed.

\section{Antenna Design}

Figure 1 shows the configuration of the presented implantable antenna, which consists of two layers of Rogers 6010 substrate. Dielectric constant and loss tangent of the substrate are, respectively, 10.2 and 0.0023 , and the thickness of each layer is $0.635 \mathrm{~mm}$. The superstrate layer is usually used to achieve biocompatibility and robustness. Two arc-shaped slots, a rectangular slot and a circular slot, are cut on the circular radiating patch to realize dual resonances and extend the effective length of the current path. In order to form a PIFA structure, one can make the designed antenna resonate at a relatively low frequency, with the first short via being located at one end of the inner arc-shaped strip. Furthermore, we place the second short via at one end of the outer arc-shaped strip to construct a shorted split ring, which is electromagnetically coupling with the inner PIFA structure. Thus, the proposed antenna is considered to be a combination of the inner PIFA structure and the outer shorted split ring. Figure 2 shows the one-layer skin simulation model, and the proposed antenna is placed in the skin model, with a distance of $3 \mathrm{~mm}$ from the upper surface of the model and a distance of $40 \mathrm{~mm}$ from the other surfaces of the model. This skin model used in this work is based on [13], and the electrical properties of the skin at $402 \mathrm{MHz}$ are $\varepsilon_{r}=46.7$ and $\sigma=0.69 \mathrm{~S} / \mathrm{m}$. The antenna was fed by a $50-\mathrm{Ohm}$ coaxial cable. The optimum dimensions of the designed antenna in Figure 1 were obtained by using electromagnetic simulation software HFSS and were listed in Table 1.

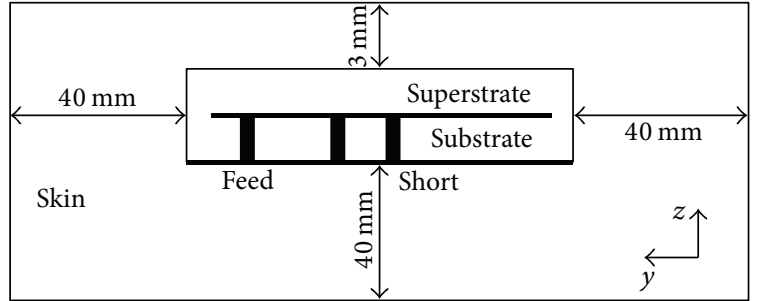

FIgURE 2: Side view of simulation model.

In this work, broad impedance bandwidth is achieved by the combination of two close resonant frequencies at $387 \mathrm{MHz}$ and $413 \mathrm{MHz}$. To better understand the operation principle of this antenna, the current distributions of the metal radiating layer at two resonant frequencies are shown in Figure 3. At $387 \mathrm{MHz}$, current flows along the same direction from the outer split ring to the inner PIFA structure, which indicates that all metal strips contribute to the low resonant frequency. At $413 \mathrm{MHz}$, the current path of the outer split ring is opposite to the inner PIFA structure, which indicates that either part of them resonates at this frequency. Thus, the antenna can obtain a broad impedance bandwidth by combining dual resonances.

In order to further explain the operation mechanism of the antenna, we considered a special case. As shown in Figure 4, we removed the outer shorted split ring and kept the inner PIFA structure of the radiating metal layer, with the same substrate and superstrate of the original one in Figure 1 and the same skin model in Figure 2 being used for comparison. As shown in Figure 5, the resonant frequency of this case is close to $413 \mathrm{MHz}$. Therefore, we can conclude that the inner PIFA structure contributes to the resonant frequency of $413 \mathrm{MHz}$. Furthermore, compared with the original antenna, the inner PIFA structure can greatly reduce antenna's size by appropriately reducing the substrate's size, but it would exhibit a narrower bandwidth. Therefore, the proposed antenna size is a compromise between miniaturization and bandwidth.

For analyzing the effect of the antenna parameters on return loss, the antenna with different short positions $\theta_{s 1}$ was simulated and compared in Figure 6 . We can conclude from Figure 6 that the smaller the angle $\theta_{s 1}$, the lower the low resonant frequency about $387 \mathrm{MHz}$. However, the short position $\theta_{s 1}$ has little effect on the resonant frequency of $413 \mathrm{MHz}$ by the simulation. The similar results could be obtained by changing the length of the outer split ring, and the longer the split ring is, the lower the low resonant frequency can be gained. Therefore, we can also conclude that the outer shorted split ring structure contributes to the low resonant frequency of $387 \mathrm{MHz}$.

\section{Measurement and Discussion}

The fabricated antenna including its superstrate is shown in Figure 7. As shown in Figure 8, we used the chopped pork phantom with the dimension of $100 \times 100 \times 50 \mathrm{~mm}^{3}$ as measurement setup, which is similar to the simulation 


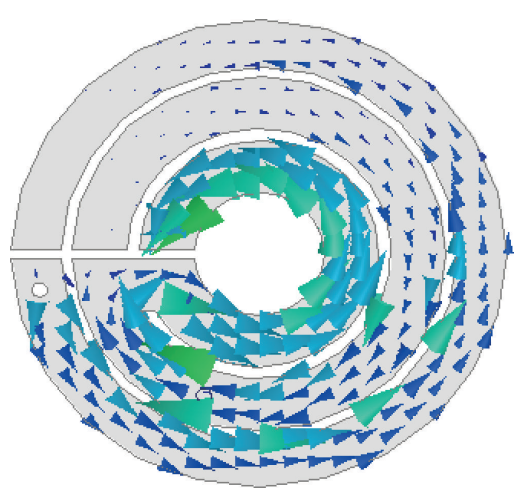

(a)

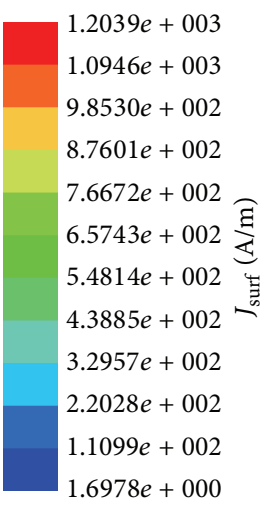

FIgURE 3: Current distributions at (a) $387 \mathrm{MHz}$ and (b) $413 \mathrm{MHz}$.

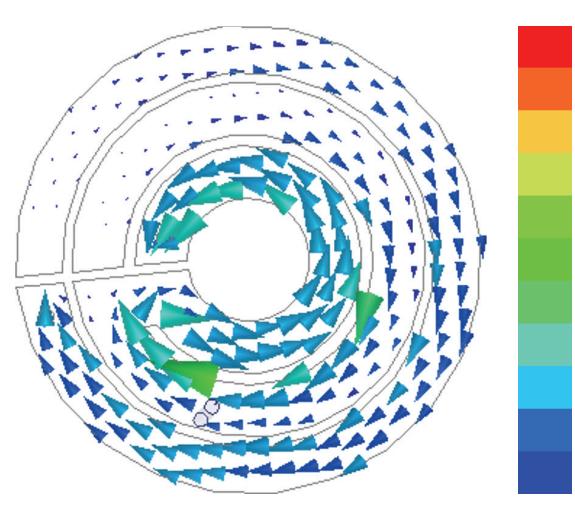

$1.3829 e+003$

$1.2573 e+003$

$1.1318 e+003$

$1.0062 e+003$

$8.8060 e+002$ $7.5503 e+002$ हิ $6.2945 e+002$ $5.0387 e+002-$ $3.7829 e+002$ $2.5271 e+002$ $1.2713 e+002$ $1.5536 e+000$

(b)

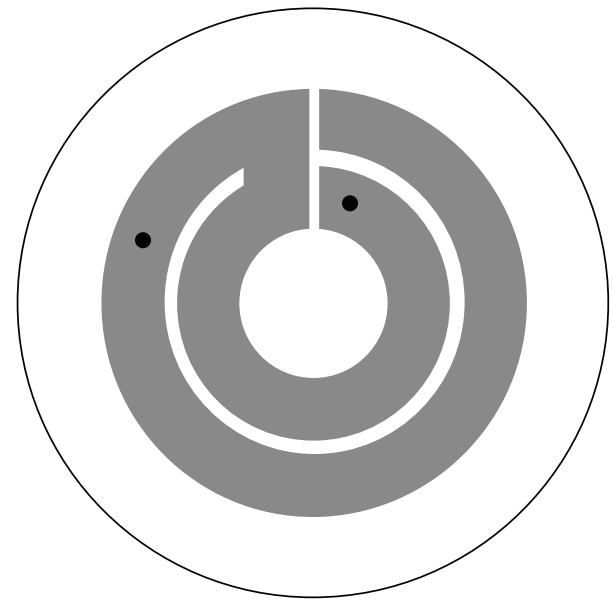

FIGURE 4: Geometry of the proposed antenna without shorted split ring.

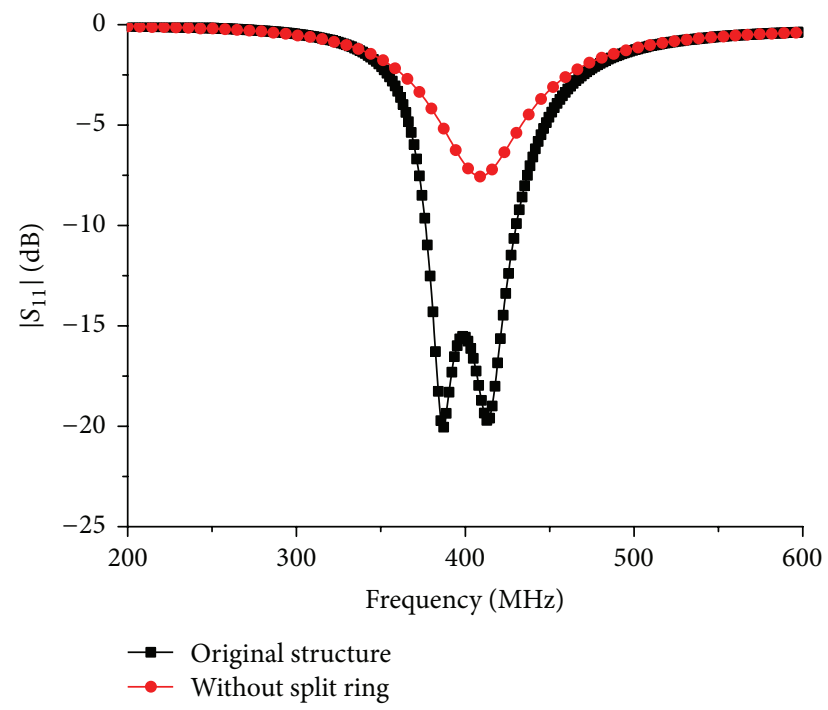

FIGURE 5: Simulated $\left|S_{11}\right|$ of the case without split ring compared to the original antenna.
TABLE 1: Antenna design parameters.

\begin{tabular}{lccc}
\hline Symbol & Value & Symbol & Value \\
\hline$R_{g}$ & $10.04 \mathrm{~mm}$ & $R_{f}$ & $6.4 \mathrm{~mm}$ \\
$R_{p}$ & $9.9 \mathrm{~mm}$ & $\theta_{f}$ & $70^{\circ}$ \\
$R_{s 1}$ & $8.9 \mathrm{~mm}$ & $R_{s 2}$ & $3.7 \mathrm{~mm}$ \\
$\theta_{s 1}$ & $10^{\circ}$ & $\theta_{s 2}$ & $20^{\circ}$ \\
$g_{1}$ & $0.4 \mathrm{~mm}$ & $g_{2}$ & $0.4 \mathrm{~mm}$ \\
$g_{3}$ & $0.5 \mathrm{~mm}$ & $w_{1}$ & $2.0 \mathrm{~mm}$ \\
$w_{2}$ & $2.2 \mathrm{~mm}$ & $w_{3}$ & $2.2 \mathrm{~mm}$ \\
\hline
\end{tabular}

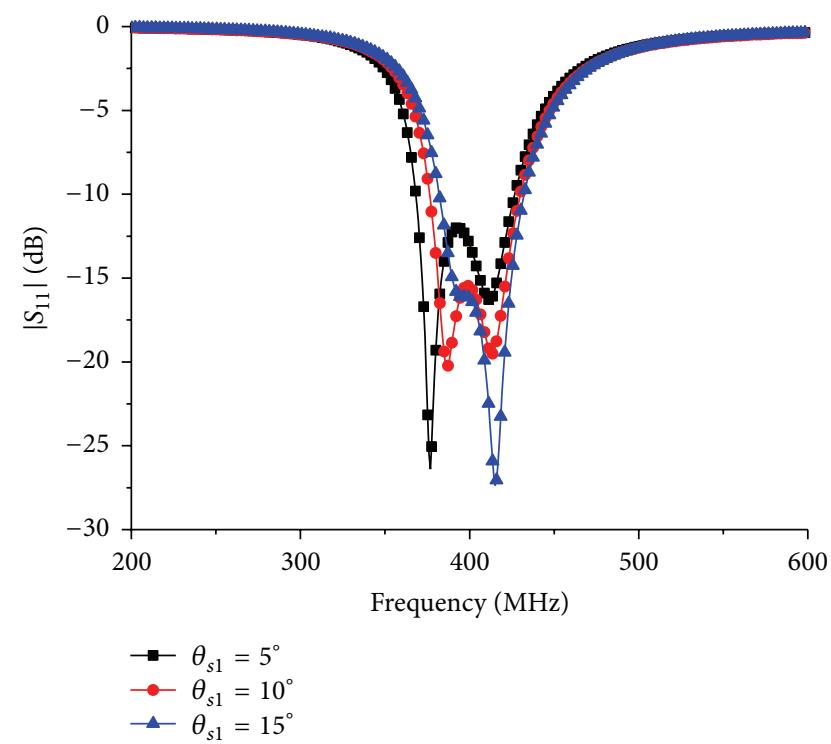

FIGURE 6: Comparison of $\left|S_{11}\right|$ of the proposed antenna with different short positions of the split ring.

model in Figure 2. According to [14], permittivity and conductivity of the chopped pork are similar with human skin in MICS band. Figure 9 shows a comparison of measured and simulated return loss of the proposed antenna. As can be seen from the graph, the measured return loss agrees well with the simulation result. The measured result indicates that broad 


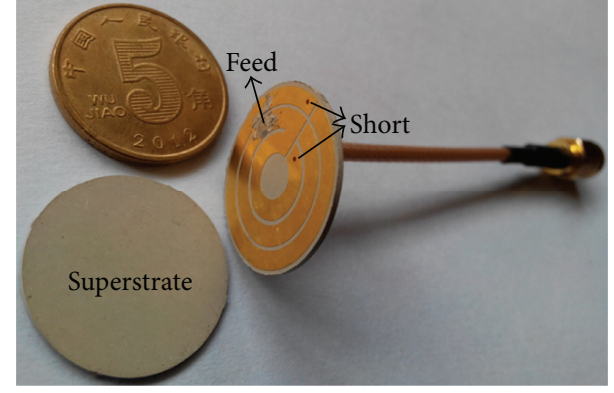

FIGURE 7: Photograph of the fabricated implantable antenna.

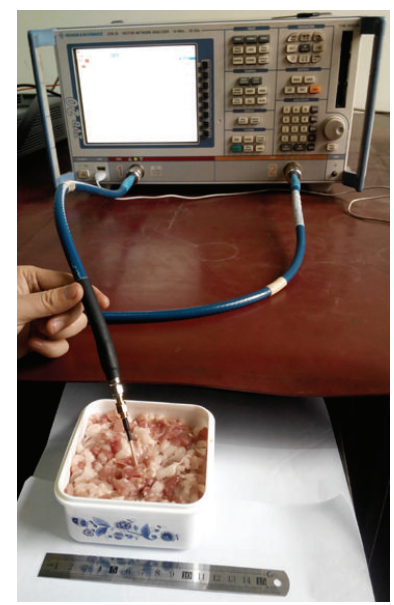

FIGURE 8: Photograph of the measurement setup.

impedance bandwidth of $55 \mathrm{MHz}$ (from 385 to $440 \mathrm{MHz}$ ) for $\left|S_{11}\right|$ below $-10 \mathrm{~dB}$ can be obtained. The unexpected fabrication tolerance and solder roughness could contribute to the slight frequency shift.

Figure 10 shows the simulated far-field gain radiation pattern of the presented antenna at $402 \mathrm{MHz}$. The pattern is almost omnidirectional, and its peak gain is $-32.9 \mathrm{dBi}$.

In addition, we evaluated the $1 \mathrm{~g}$ averaged specific absorption rate (SAR) for the human body safety concern [15]. Provided that $1 \mathrm{~W}$ power is delivered to the presented antenna, the maximum SAR value of $319.8 \mathrm{~W} / \mathrm{kg}$ at the $402 \mathrm{MHz}$ can be obtained. Therefore, the allowed transmitter power should be decreased to $5 \mathrm{mw}$ for satisfying the $1 \mathrm{~g}$ SAR regulation.

The size, bandwidth, and peak gain of the proposed antenna are compared with the previous implantable planar antennas with the sing-layer metal patch and the full ground plane at MICS band as shown in Table 2.

\section{Conclusions}

By embedding two arc-shaped slots, a rectangular slot and a circular slot on a circular radiating metal patch, a novel dual-resonant implantable antenna at MICS band has been presented. Compared with the previous similar implantable antennas, the proposed antenna incorporates three advantages: broad bandwidth, compact structure, and

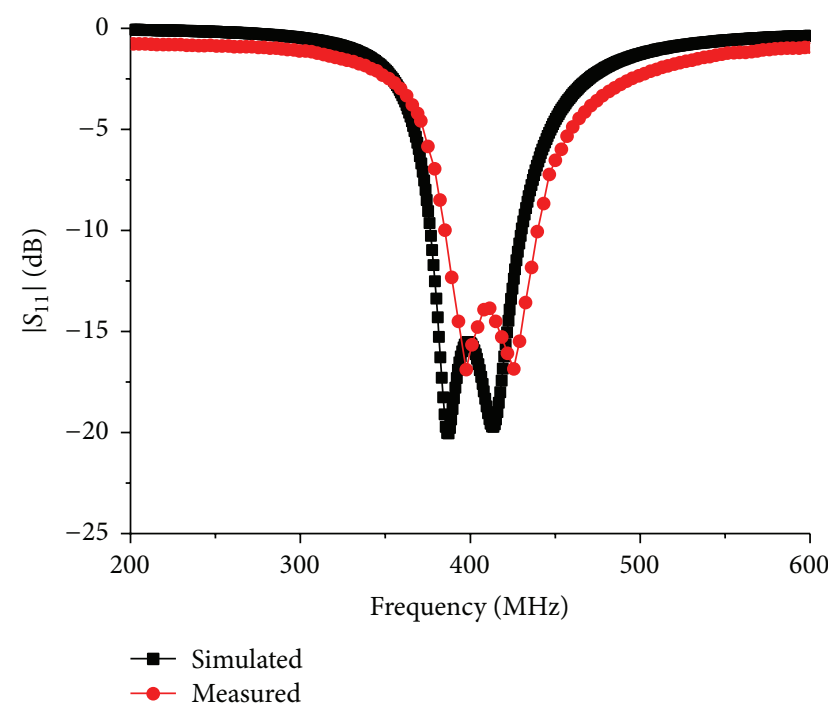

FIGURE 9: Comparison of the simulated and measured $\left|S_{11}\right|$ of the proposed antenna.

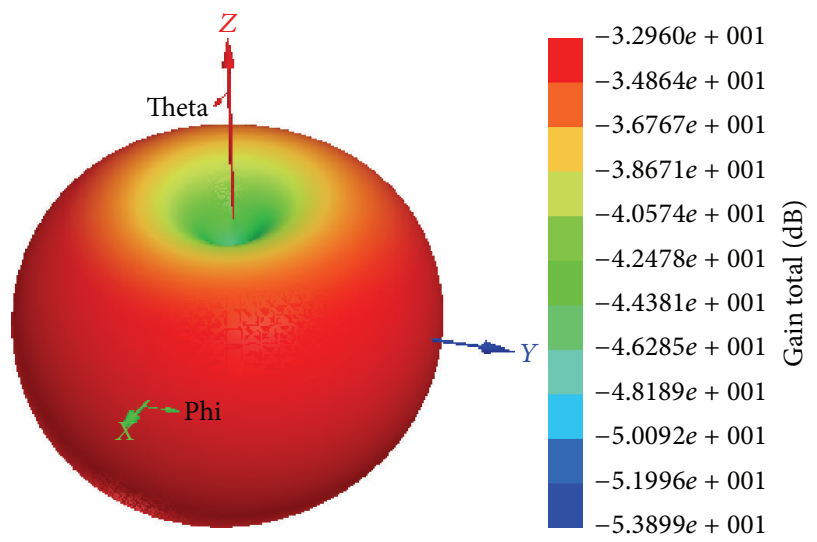

FIGURE 10: Simulated three-dimensional gain patterns for the proposed implantable antenna at $402 \mathrm{MHz}$.

TABLE 2: Characteristic comparisons of the similar implantable antennas.

\begin{tabular}{lccc}
\hline $\begin{array}{l}\text { Implantable } \\
\text { antenna }\end{array}$ & $\begin{array}{c}\text { Volume } \\
\left(\mathrm{mm}^{3}\right)\end{array}$ & $\begin{array}{c}10 \mathrm{~dB}-\mathrm{BW} \\
(\mathrm{MHz})\end{array}$ & Peak gain $(\mathrm{dBi})$ \\
\hline$[3]$ & 3457.4 & 20 & - \\
{$[4]$} & 1024 & 20 & - \\
{$[5]$} & 823 & 25 & - \\
{$[7]$} & 198.4 & 25 & -32.5 \\
{$[8]$} & 642.9 & 80 & -25.1 \\
\hline This paper & 431.5 & 55 & -32.9 \\
\hline
\end{tabular}

friendly shape. Good agreement is obtained between the simulation and measurement for the return loss. Evaluation of the radiation performance and the safety consideration shows that the proposed antenna is suitable for biotelemetry communication. 


\section{Competing Interests}

The authors declare that there are no competing interests regarding the publication of this paper.

\section{Acknowledgments}

This work was supported by the Chinese Postdoctoral Science Foundation (2014M562292), the Sichuan Provincial Science and Technology Planning Project of China (2015FZ0112), and the National Natural Science Foundation of China (61271028).

\section{References}

[1] A. Kiourti and K. S. Nikita, "A review of implantable patch antennas for biomedical telemetry challenges and solutions," IEEE Transactions on Antennas and Propagation, vol. 54, no. 3, pp. 210-228, 2012.

[2] A. Kiourti and K. S. Nikita, "Implantable antennas: a tutorial on design, fabrication, and in vitro/in vivo testing," IEEE Microwave Magazine, vol. 15, no. 4, pp. 77-91, 2014.

[3] P. Soontornpipit, C. M. Furse, and Y. C. Chung, "Design of implantable microstrip antenna for communication with medical implants," IEEE Transactions on Microwave Theory and Techniques, vol. 52, no. 8, pp. 1944-1951, 2004.

[4] J. Kim and Y. Rahmat-Samii, "Implanted antennas inside a human body: simulations, designs, and characterizations," IEEE Transactions on Microwave Theory and Techniques, vol. 52, no. 8, pp. 1934-1943, 2004.

[5] W. Huang and A. A. Kishk, "Embedded spiral microstrip implantable antenna," International Journal of Antennas and Propagation, vol. 2011, Article ID 919821, 6 pages, 2011.

[6] L.-J. Xu, Y.-X. Guo, and W. Wu, "Miniaturised slot antenna for biomedical applications," Electronics Letters, vol. 49, no. 17, pp. 1060-1061, 2013.

[7] H. Li, Y.-X. Guo, C. R. Liu, S. Q. Xiao, and L. Li, "A miniatureimplantable antenna for MedRadio-band biomedical telemetry," IEEE Antennas and Wireless Propagation Letters, vol. 14, pp. 1176-1179, 2015.

[8] C.-M. Lee, T.-C. Yo, F.-J. Huang, and C.-H. Luo, "Dualresonant $\Pi$-shape with double L-strips PIFA for implantable biotelemetry," Electronics Letters, vol. 44, no. 14, pp. 837-839, 2008.

[9] C.-L. Tsai, K.-W. Chen, and C.-L. Yang, "Implantable wideband low-SAR antenna with C-shaped coupled ground," IEEE Antennas and Wireless Propagation Letters, vol. 14, pp. 1594-1597, 2015.

[10] L.-J. Xu, Y.-X. Guo, and W. Wu, "Bandwidth enhancement of an implantable antenna," IEEE Antennas and Wireless Propagation Letters, vol. 14, pp. 1510-1513, 2015.

[11] A. Kiourti and K. S. Nikita, "Miniature scalp-implantable antennas for telemetry in the MICS and ISM bands: design, safety considerations and link budget analysis," IEEE Transactions on Antennas and Propagation, vol. 60, no. 8, pp. 3568-3575, 2012.

[12] A. Kiourti, J. R. Costa, C. A. Fernandes, and K. S. Nikita, "A broadband implantable and a dual-band on-body repeater antenna: design and transmission performance," IEEE Transactions on Antennas and Propagation, vol. 62, no. 6, pp. 28992908, 2014.

[13] T. Karacolak, A. Z. Hood, and E. Topsakal, "Design of a dualband implantable antenna and development of skin mimicking gels for continuous glucose monitoring," IEEE Transactions on Microwave Theory and Techniques, vol. 56, no. 4, pp. 1001-1008, 2008.

[14] T. Karacolak, R. Cooper, E. S. Unlu, and E. Topsakal, “Dielectric properties of porcine skin tissue and in vivo testing of implantable antennas using pigs as model animals," IEEE Antennas and Wireless Propagation Letters, vol. 11, pp. 16861689, 2012.

[15] "IEEE standard for safety levels with respect to human exposure to radio frequency electromagnetic fields, $3 \mathrm{kHz}$ to $300 \mathrm{GHz}$," IEEE Standard 95, 1999. 


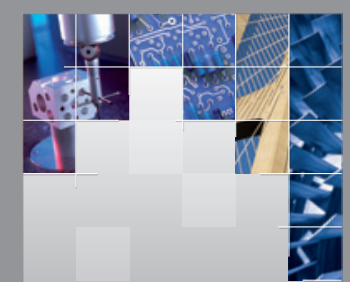

\section{Enfincering}
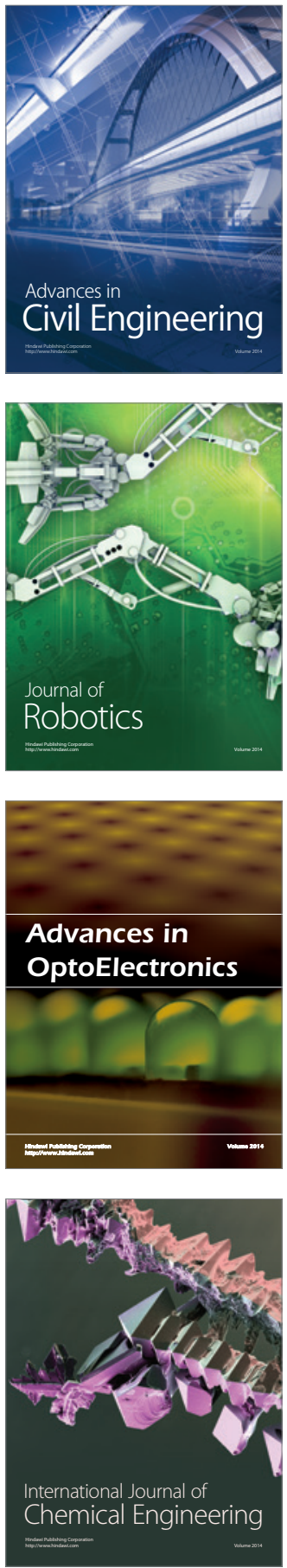

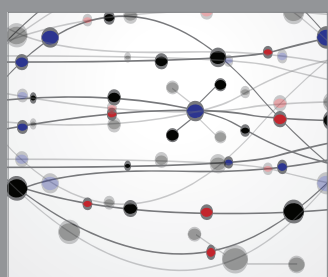

The Scientific World Journal

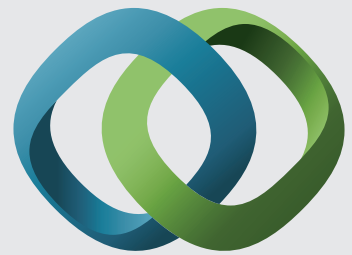

\section{Hindawi}

Submit your manuscripts at

http://www.hindawi.com
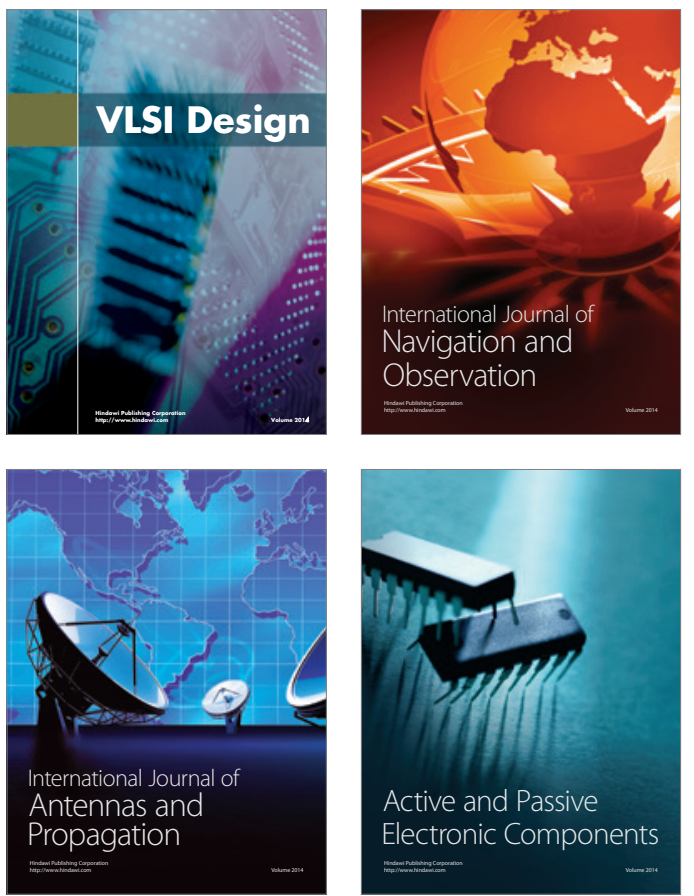
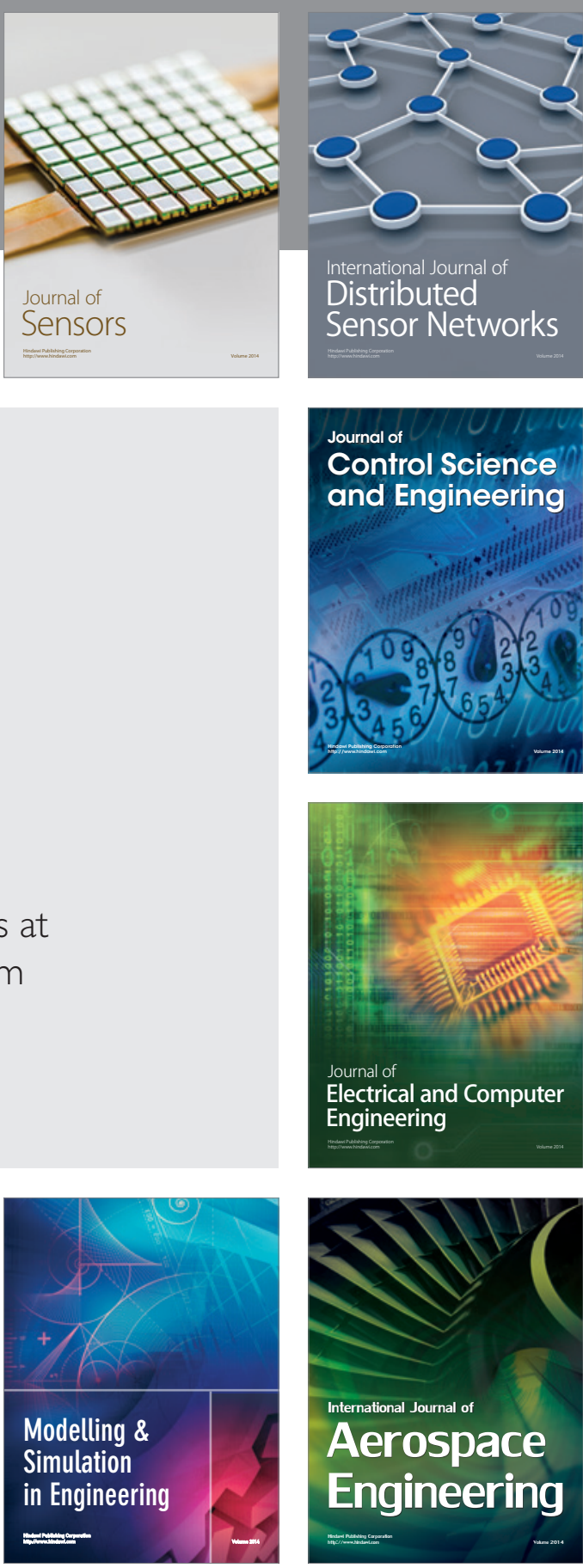

International Journal of

Distributed

Sensor Networks

Journal of

Control Science

and Engineering
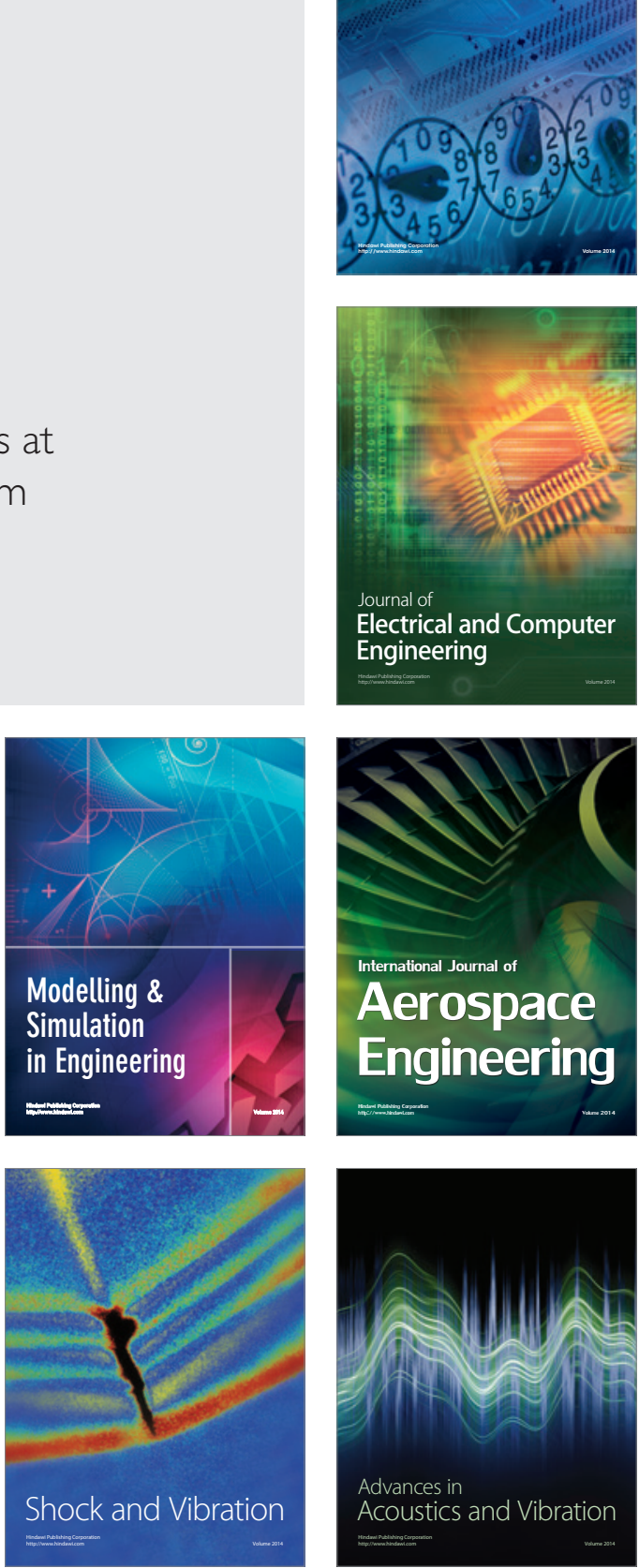